\title{
The Effect of Hypnotherapy on Anticipatory Nausea in Head and Neck Cancer Patients Undergoing Chemotherapy
}

\author{
Dadi Hamdani ${ }^{1}$, Awal Prasetyo ${ }^{2}$, Anggorowati $^{3}$ \\ ${ }^{1}$ Department of Nursing, STIKes Muhammadiyah Ciamis, Indonesia \\ ${ }^{2}$ Faculty of Medicine, Universitas Diponegoro, Semarang, Indonesia \\ ${ }^{3}$ Department of Nursing, Faculty of Medicine, Universitas Diponegoro, Semarang, Indonesia \\ Corresponding Author: Dadi Hamdani (dadi_ham@yahoo.co.id)
}

Received: 20 October 2019

Revised: 29 November 2020

Accepted: 7 December 2020

\begin{abstract}
Background: One of the chemotherapy side effects on head and neck cancer patients is anticipatory nausea. However, the anticipatory nausea problem has not been properly resolved. Nausea might be psychologically reduced by hypnotherapy. There only have been very few studies conducted to examine the effects of hypnotherapy in alleviating anticipatory nausea.

Purpose: This study aimed to determine the effect of hypnotherapy using Hanung induction technique on anticipatory nausea in head and neck cancer patients undergoing chemotherapy.

Methods: This research employed a pre-post test of quasi-experiment with control group design. Consecutive sampling technique was used to obtain 64 subjects who met inclusion and exclusion criteria and were equally divided into the intervention and control groups. Hypnotherapy as the intervention was carried out in two sessions, each of which lasted for 20 minutes, with a week distance between sessions. The data were collected using a visual analog scale (VAS), which was used twice to measure anticipatory nausea and analyzed using the paired and independent-sample t-test.

Result: The results showed that the mean score of anticipatory nausea in the intervention group reduced from $7.6 \pm 1.4$ to $2.3 \pm 1.2$ after hypnotherapy, while the mean in the control group increased from $6.4 \pm 1.6$ to $6.7 \pm 1.4$. There was a significant difference in the score of anticipatory nausea after the implementation of hypnotherapy between the intervention and the control group $(p<0.001)$.

Conclusion: The study concluded that hypnotherapy is effective in reducing the intensity of anticipatory nausea in head and neck cancer patients undergoing chemotherapy. Therefore, hypnotherapy can be applied by oncology nurses as an intervention in treating anticipatory nausea.
\end{abstract}

Keywords: Head and neck cancer; anticipatory nausea; chemotherapy; hypnotherapy

How to Cite: Hamdani, D., Prasetyo, A., \& Anggorowati, A. (2020). The effect of hypnotherapy on anticipatory nausea in head and neck cancer patients undergoing chemotherapy. Nurse Media Journal of Nursing, 10(3), 317-328. doi:10.14710/nmjn.v10i3.26027

Permalink/DOI: https://doi.org/10.14710/nmjn.v10i3.26027 


\section{BACKGROUND}

Head and neck cancer was the seventh most common cancer worldwide, with 890,000 new cases and 450,000 deaths (Bray et al., 2018). Head and neck cancer is the third common cancer in Indonesia (Ministry of Health Republic of Indonesia [MoHRI], 2018a). The Health Research and Development Agency of the Republic of Indonesia notes that the number of cancer patients in Central Java was 132,565 in 2018 (MoHRI, 2018b). Cancer must be controlled through chemotherapy treatment to reduce mortality. However, chemotherapy can cause patients to experience severe anticipatory nausea (Prapti, Petpichetchian \& Chongchareon, 2012).

Anticipatory nausea creates a significant burden on patients and increases the potential to leave treatment. This is due to the patients' bad experience at the time of chemotherapy that was previously undertaken. Anticipatory nausea is a symptom of nausea in patients undergoing a chemotherapy program and occurs just before the chemotherapy injection is given (Rao, 2012). Anticipatory nausea is mediated by anxiety which affects the vomiting center in the brain stem (Stitch, Rock, Limebeer \& Parker, 2014). Anticipatory nausea is a common complaint among cancer patients and is often based on the progression of chemotherapy-induced nausea. The nausea is reported by $20 \%-50 \%$ of patients, in which the frequency and intensity increase during the chemotherapy cycle (Kamen et al., 2014; Molassiotis et al., 2016). Anticipatory nausea is one of the causes of discontinuation or early termination of chemotherapy in head and neck cancer patients. It was found that $30 \%$ of the cancer patients stopped chemotherapy due to complaints of anticipatory nausea (Mustian et al., 2011).

The trigger for the emergence of anticipatory nausea is caused by the patients' experience during previous chemotherapy. Patients who receive the doxorubicin cytostatic regimen in red color with nausea experience will experience nausea again in the next chemotherapy program. Each time the patients see a red color cytostatic regimen given to them, they imagine the previous chemotherapy experience, and it triggers nausea anticipatory that occurs before the injection of chemotherapy regimens. It suggests that this type of nausea is difficult to control by antiemetics (nausea-reducing drugs) because it is triggered by psychological factors (Kamen et al., 2014; Kravits, 2015;).

Psychological factors are stimuli that are most often discussed with anticipatory nausea, which arises from olfactory stimulation and cognitive stimulation. Another factor that has been identified to contribute to nausea in association with conditioning is the suggestion (Roscoe, Morrow, Aapro, Molassiotis \& Olver, 2011). A suggestion is the patients' belief that they will experience nausea during chemotherapy. This significantly increases the risk of the occurrence of nausea. Those who believed it was "very likely" that they would have severe nausea from chemotherapy were five times more likely to experience severe nausea than fellow patients who thought its occurrence would be "very unlikely" (Kamen et al., 2014).

Non-pharmacological approaches, which include behavioral interventions, can be reviewed in relieving symptoms of chemotherapy. However, little evidence supports the use of complementary and alternative methods in eliminating anticipatory nausea. Behavioral interventions and hypnotherapy, particularly systematic desensitization, 
should be reviewed to prevent and treat anticipatory nausea (Figueroa-Moseley et al., 2012). Hypnotherapy is a psychotherapeutic technique conducted between a patient and a trained clinician who uses therapeutic suggestions to produce changes in perception, cognition, affect, mood, behavior, and sensation that are deemed desirable by both parties (Kamen et al., 2014; Kravits, 2015). Hypnotherapy can influence and access the limbic system, namely the amygdala in the human brain. It can instill suggestions, change perceptions and affect the emotional situation of feelings through the subconscious, theta waves (Barber \& Wilson, 2011; Hamdani, Prasetyo \& Anggorowati, 2019; Kendrick, 2012).

Research shows that hypnotherapy with the pendulum induction technique can treat anticipatory nausea and is even more valuable for preventing anticipatory nausea progression when used before starting chemotherapy (Garba \& Mamman, 2019). Furthermore, the use of shock induction techniques and the hypnotherapy stage also affect anticipatory nausea experienced by cancer patients undergoing chemotherapy (Richardson et al., 2007). Pendulum, guided imagination and shock induction techniques in hypnotherapy often make patients feel dizzy after the hypnotherapy session ends and must provide a long time for nurses to provide complete therapy. Therefore, other induction techniques need to be considered in hypnotherapy to prioritize comfort (Kravits, 2015). A comfortable induction technique is introduced by Hanung induction hypnotherapy. This technique is done by gently massaging the neguan, yintang, and tayiang acupuncture points, accompanied by giving suggestions with a blend of conventional hypnosis, awareness, quantum touch, and neuro-linguistic programming (Prasetya, 2017; Prasetya, Murti \& Anantanyu, 2018).

Previous studies have applied Hanung induction hypnotherapy to increase compliance for the treatment of TB patients. The results showed that this hypnotherapy technique increases adherence in the treatment undertaken, and patients get a sense of security and comfort with the method of induction technique given (Prasetya, 2017; Prasetya et al., 2018). The Hanung induction technique provides a gentle touch to the three points of the forehead, temples, and hands, so this hypnotherapy technique is safe to apply in the clinic. In previous studies, hypnotherapy using pendulum induction techniques, shock, and guided imagination, was found to cause dizziness after the hypnotherapy session ended, resulting in a longer time for nurses to complete therapy. Therefore, it is important to investigate how Hanung induction hypnotherapy reduces anticipatory nausea in head and neck cancer patients undergoing chemotherapy.

\section{PURPOSE}

This study aimed to determine the effect of hypnotherapy using Hanung induction technique on anticipatory nausea in head and neck cancer patients undergoing chemotherapy.

\section{METHODS}

\section{Research design and sample}

This study was a quasi-experimental study using pre and post-test design with a control group. A consecutive sampling technique was used to recruit subjects who met the inclusion and exclusion criteria. The study was conducted in the chemotherapy unit of a 
regional hospital in Central Java, Indonesia, in May-June 2019 with a total sample of 64 participants, assigned to two groups, i.e., the intervention and the control group. The intervention group consisted of 32 participants receiving hypnotherapy intervention and antiemetic therapy, whereas the control group consisted of 32 participants receiving only antiemetic therapy according to clinical standards. The inclusion criteria of this study were head and neck cancer patients who experienced anticipatory nausea, had never received hypnotherapy before, able to follow orders during the research process, were willing to become respondents, and followed research procedures. The exclusion criteria were patients with anxiety, acute psychosis, dementia, paranoid or compulsive obsession, and had wounds in three areas of massage points (neiguan/wrist, taiyang/temples, and yintang/forehead), not easily hypnotized (hard susceptibility of Barber Suggestibility Test). The participants' flowchart in this study was presented in Figure 1.

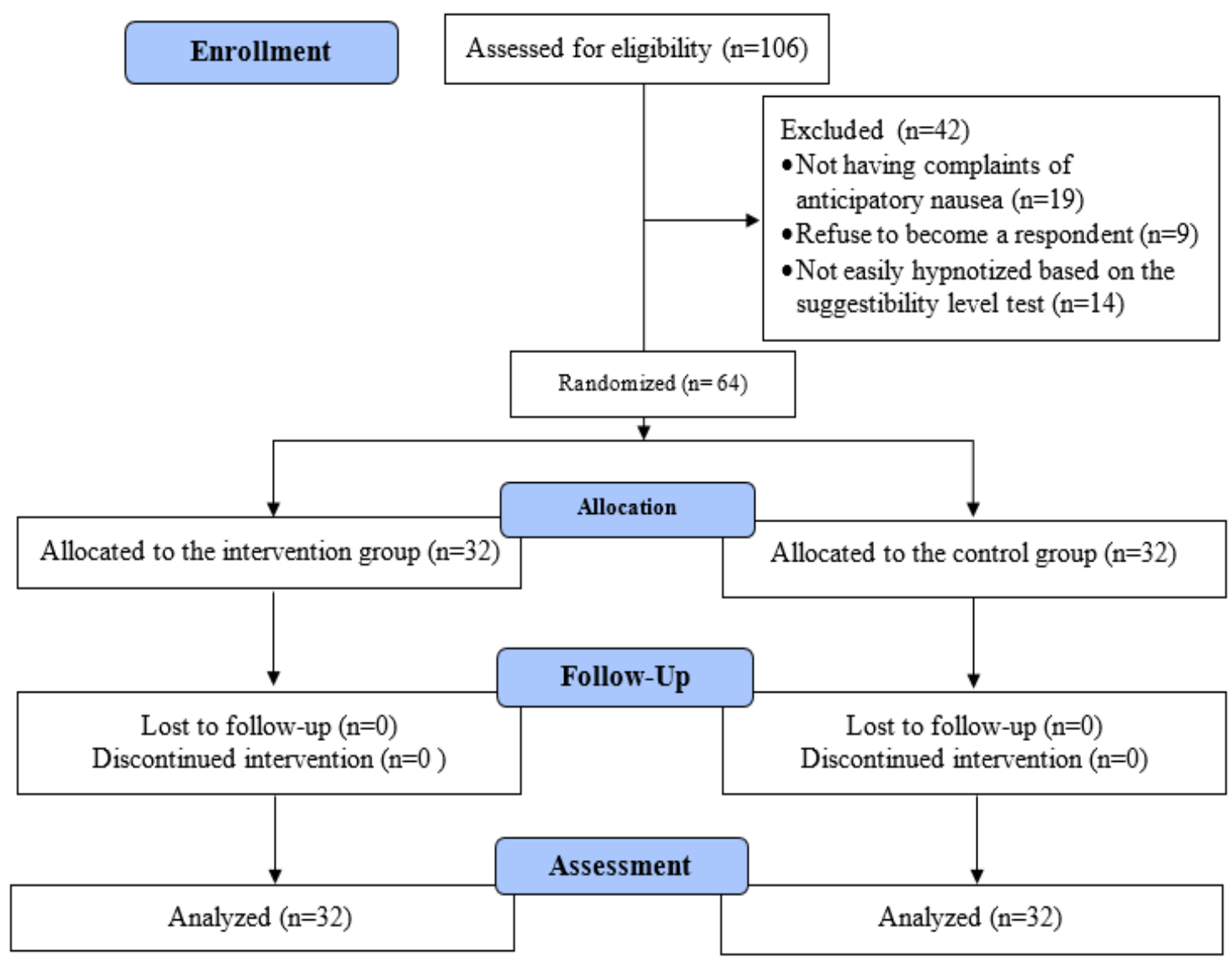

Figure 1. Participants' flowchart

\section{Measurements}

The measurement of the anticipatory nausea level was performed using the visual analog scale (VAS), of which the patients were asked to mark the point on a horizontal line along $10 \mathrm{~cm}$. VAS instrument was a valid measuring instrument with the reliability of 0.95 , validity of $r=0.62$, and had been used to rate and monitor the severity of nausea in the emergency department (Meek, Kelly \& Hu, 2019). VAS was an instrument designed to 
measure internal feelings such as sensation, experience, and perception (Lee \& Kieckhefer, 2011; Van den Bosch, Moons, Bonsel \& Kalkman, 2010). VAS was used in this study as it was considered the best method for measuring nausea experienced by the patients. Also, it had been used in previous studies to measure nausea (Billhult, Bergbom \& Stener-Victorin, 2007; Grealish, Lomasney \& Whiteman, 2000). Measurement of nausea was done twice, once before the first hypnotherapy and once again after the second session of hypnotherapy. Barber suggestibility test was also used to determine the level of client susceptibility to hypnosis. The barber suggestibility test had two levels, namely, hard susceptibility and easy susceptibility. Hard susceptibility was scored when respondents could not respond to suggestions and instructions given by the therapist to lock/attach both hands, while easy susceptibility was marked when respondents could respond to the same suggestions and instructions (Barber \& Wilson, 2011; Roy, 2010).

\section{Intervention}

The intervention began with a pre-test of patients who experienced anticipatory nausea and had met the inclusion criteria. Hypnotherapy was given 30 minutes before cytostatic injection followed by antiemetic after hypnotherapy. Hypnotherapy interventions were given by a certified therapist and carried out for two sessions with one week apart between sessions, each of which lasted for 20 minutes. The stages of hypnotherapy were: (1) preinduction, which was an opening conversation to build patients' confidence for the therapy, minimize feelings of fear, and provide explanations of hypnotherapy; (2) suggestibility test to identify the level of patients' suggestion using Barber suggestibility test; (3) induction process using Hanung induction technique with a massage on wrist, temples, and forehead area for 2-5 minutes each area with a clockwise massage; (4) deepening, a process to bring the patients into a deeper trance; (5) instilling suggestion (therapeutic) to give positive suggestions to patients until embedded in the subconscious mind and to make positive changes for patients, e.g "Open the subconscious mind wide... from now on, when given chemotherapy, your body will enjoy comfort, you will feel the freshness, and when your hands are rubbing your throat, your body will be more comfortable, and when you see the nurse, you feel calm and become very relaxed and comfortable"; and (6) termination to bring patients from his hypnotic state towards full consciousness. Around 10 minutes after the hypnotherapy session ended, a post-test was conducted using the visual analog scale. In the control group, participants were only tested for nausea on the first week and the second week with only given antiemetics as the standard care.

\section{Data analysis}

The characteristics of participants, such as gender, age, and status performance, were analyzed using descriptive statistics. The homogeneity of the two groups was tested using the Chi-square test. The data normality on anticipatory nausea was examined using the Shapiro Wilk test, and the result showed that the data were normally distributed. Therefore, the paired t-test was used to analyze the difference in the mean score of anticipatory nausea before and after the intervention, while the independent t-test was used to compare the mean score of anticipatory nausea between the intervention and the control groups. 


\section{Ethical consideration}

This study was approved by the Health Research Ethics Committee of Dr. Moewardi Hospital Surakarta with the number 633/V/HREC/2019. Informed consent was obtained from all patients. Important information related to the purpose of the study, procedures, risks, and benefits of the study were explained to the patients. The confidentiality of the patients was also maintained throughout the study.

\section{RESULTS}

\section{Characteristics of the participants}

The results showed that the participants in the intervention and control groups were homogenous ( $p>0.05$ ). As shown in Table 1, most participants in both groups were late adults (41-65 years old) and unable to carry on normal activities. The intervention group was dominated by men, while the control group were dominated by women.

Table 1. Characteristics of participants $(n=64)$

\begin{tabular}{|c|c|c|c|c|c|}
\hline \multirow{3}{*}{ Characteristics } & \multicolumn{4}{|c|}{ Groups } & \multirow{3}{*}{$p$} \\
\hline & \multicolumn{2}{|c|}{$\begin{array}{l}\text { Intervention Group } \\
\qquad(\mathrm{n}=32)\end{array}$} & \multicolumn{2}{|c|}{$\begin{array}{l}\text { Control Group } \\
\quad(\mathrm{n}=32)\end{array}$} & \\
\hline & $f$ & $\%$ & $f$ & $\%$ & \\
\hline \multicolumn{6}{|l|}{ Gender } \\
\hline Male & 15 & 47 & 18 & 56 & \multirow{2}{*}{$0.453 *$} \\
\hline Female & 17 & 53 & 14 & 44 & \\
\hline \multicolumn{6}{|l|}{ Age } \\
\hline Early Adult (18-40 years old) & 5 & 16 & 4 & 12.5 & \multirow{2}{*}{$0.338 *$} \\
\hline Late Adult (41-65 years old) & 27 & 84 & 28 & 87.5 & \\
\hline \multicolumn{6}{|l|}{ Performance Status } \\
\hline $\begin{array}{l}\text { Able to carry on normal } \\
\text { activities }\end{array}$ & 14 & 44 & 11 & 34 & \multirow[b]{2}{*}{$0.856^{*}$} \\
\hline $\begin{array}{l}\text { Unable to carry on normal } \\
\text { activities }\end{array}$ & 18 & 56 & 21 & 66 & \\
\hline
\end{tabular}

Differences in the anticipatory nausea score before and after the intervention

Table 2 showed that after the hypnotherapy, the mean score of anticipatory nausea in the intervention group reduced from $7.6 \pm 1.4$ to $2.3 \pm 1.2$, while in the control group, the mean increased from $6.4 \pm 1.6$ to $6.7 \pm 1.4$. The anticipatory nausea score in the intervention group $(p=0.001)$ decreased significantly compared to the control group $(p=0.107)$

Table 2. Differences in nausea pre and post-intervention $(n=64)$

\begin{tabular}{lccccc}
\hline Group & $\begin{array}{c}\text { Pre-test } \\
M e a n \pm S D\end{array}$ & $\begin{array}{c}\text { Post-test } \\
\text { Mean } \pm S D\end{array}$ & $\begin{array}{c}\text { Mean } \\
\text { Difference }\end{array}$ & $t$ & $p$ \\
\hline Intervention & $7.6 \pm 1.4$ & $2.3 \pm 1.2$ & 5.3 & 22.2 & $0.001^{*}$ \\
\hline Control & $6.4 \pm 1.6$ & $6.7 \pm 1.4$ & -0.3 & -1.6 & $0.107^{*}$ \\
\hline
\end{tabular}

*Paired t-test 


\section{Differences in the anticipatory nausea reduction after intervention in both groups}

Table 3 showed that there was a significant difference in the mean differences between the intervention and control group $(p=0.001)$ after hypnotherapy. It can be concluded that there was a positive effect of hypnotherapy on the reduction of anticipatory nausea in patients with head and neck cancer undergoing chemotherapy.

Table 3. Difference means nausea between the two groups $(n=64)$

\begin{tabular}{lcccccc}
\hline Mean Differences & \multicolumn{2}{c}{$\begin{array}{c}\text { Intervention Groups } \\
\text { (post-test) }\end{array}$} & \multicolumn{2}{c}{$\begin{array}{c}\text { Control Groups } \\
\text { (post-test) }\end{array}$} & $t$ & $p$ \\
\cline { 2 - 7 } & $M D$ & $S D$ & $M D$ & $S D$ & & \\
\hline Nausea & 5.3 & 1.3 & -0.3 & 0.9 & 13.0 & $0.001^{*}$ \\
\hline *Independent t-test & & & & & &
\end{tabular}

\section{DISCUSSION}

This study investigated the effect of hypnotherapy on anticipatory nausea in patients with cancer undergoing chemotherapy. The results showed a positive effect of hypnotherapy on reducing anticipatory nausea in cancer patients undergoing chemotherapy. This finding is similar to a previous study that hypnotherapy can reduce nausea, anxiety, and psychological pressure in cancer patients undergoing chemotherapy (Booth, 2020; Carlson et al., 2018; Richardson et al., 2007). Similarly, another study also showed that hypnotherapy could reduce nausea (Kravits, 2015).

Hypnotherapy is defined as a therapy carried out by a hypnotherapist to patients for hypnosis by providing encouragement or suggestions for healing (Hakim, 2009). Hypnotherapy is all types of utilization of hypnosis for therapeutic purposes, both physical and mental therapies. Hypnosis is a state of mind where attention becomes very focused, so the level of suggestibility (acceptability) increases. Hypnosis is a penetrating area of criticism of the conscious mind and acceptance of certain thoughts. Someone who is in a hypnotic state will display several different characteristics and tendencies compared to someone who is not in a hypnotic state. In a hypnotic state, a person is more likely to accept encouragement or suggestions. Hypnotherapy relies on the mechanism of the human mind, namely the conscious and the subconscious minds. Hypnotherapy provides direction, encouragement, and suggestions that generate self-power and enlighten creative thoughts that are directed directly at the human subconscious mind (Assen, 2016; Umami, Sudalhar, Pratama, Fitri \& Firmansyah,, 2020).

A physiological state will occur when hypnosis is carried out, such as drowsiness and relaxedness. Nerve nodes in human beings stimulate the production of neurotransmitters, which are brain chemicals such as serotonin, dopamine, norepinephrine, and noradrenaline that are used to relay, modulate, and strengthen signals between neurons and other cells. These brain chemicals products are then absorbed by the hippocampus and distributed to all brain cells. The products include: (1) endorphins that make the persons happy, excited, cheerful, and motivated; (2) enkephalin that make the persons calm, relaxed, comfortable, and far more focused; (3) beta-endorphins that make the persons not easily discouraged, whiny, or ashamed and more trustworthy; and (4) melatonin that makes the eyes tired, sleepy, lazy, and comfortable. These regulate a 
person's emotional behavior and valves when he cries, screams, gets angry, and sings (Carlson et al., 2018).

Hypnotherapy using the Hanung induction technique promoted non-shock induction because it was done by gently massaging the neguan, yintang, and tayiang acupuncture points accompanied by giving suggestions. Hanung induction is a blend of conventional hypnosis, awareness, quantum touch, and neuro-linguistic programming. Conventional hypnosis involves relaxation until the patient is in a trance. Mindfulness facilitates awareness by providing suggestions during acupoints' massage with the appropriate rhythm of words following the patient's breathing rhythm. Quantum touch is sincerely done during massage and intended for the good of the patient. Neuro-linguistic programming helps to provide suggestions according to the type of modality, condition, and condition of the patient. As Hanung induction hypnotherapy combines various techniques, it results in a fast, safe, and comfortable reaction to put the patient into a hypnotic trance (Prasetya et al., 2018). So, this hypnotherapy technique is highly recommended for nausea cancer patients undergoing chemotherapy.

This study showed that hypnotherapy could enter the human subconscious mind with sentences delivered by researchers so that it gives an influence for chemotherapy patients who hear them. It is implied that the patients feel comfortable, do not experience nausea, and are more excited about undergoing chemotherapy (Robert, Kenneth, \& Paul, 2011). Based on the adaptation theory, giving hypnotherapy induction can improve a patient's adaptive response by manipulating external contextual stimuli (positive suggestions) so that some psychological effects arising from the presence of stressors can be conditioned adaptively to control anticipatory nausea (Janie, 2015).

The result of this study showed that the anticipatory nausea score before the intervention was moderate-high. It means that the head and neck cancer patients undergoing chemotherapy generally experience moderate to high anticipatory nausea. This result is supported by Kamen et al. (2014) and Molassiotis et al. (2016), who claimed that 20\%$50 \%$ of chemotherapy patients reported anticipatory nausea, and it could increase during the therapy. Chemotherapy patients experience anticipatory nausea that is triggered by emotional, cognitive, and anxiety responses by remembering the previous chemotherapy experience. Nausea occurs again when the patients are undergoing further chemotherapy treatment (Roscoe et al., 2011). Anticipatory nausea is mediated by anxiety related to unpleasant feelings, vision, smell, memory of cytostatic drugs, and fears that are responded through the limbic system (visual-vestibular mismatch), which then stimulates the thalamus and is mediated by the neocortex of the amygdala, which is a part of the central telencephalon for long-term memory. This type of nausea is difficult to control (Kamen et al., 2014; Kravits, 2015). The belief of a patient that he will experience nausea during chemotherapy will significantly increase the risk of nausea (Navari, 2016; Roscoe et al., 2011).

This study found that anticipatory nausea in head and neck cancer patients undergoing chemotherapy was more common in men over 40 years of age. This result is supported by Mosa, Hossain, Lavoie \& Yoo (2020), who found a higher proportion of men who had head and neck cancer accompanied by anticipatory nausea. At the age of 40 years and 
over, the lower esophageal muscle weakens; this is also caused by the influence of drugs consumed to reduce symptoms of chronic disease. This muscle is supposed to contract and close the channel to the esophagus after food has passed into the stomach. When muscles are weak, the throat will remain open, and stomach acid may rise back into the esophagus that causes nausea (D'Souza et al., 2014). When a man has a terminal illness and is required long-term treatment, it is a psychological impact that creates stress. Man hormones do not develop under stress. This stress hormone creates new havoc for the body. Stress can trigger feelings of nausea (Jung, Tae, Moon, Kim \& Shim, 2019). Sometimes adult patients with terminal illness also lose complex health management, including support from family and fellow patients (Husain, Kusuma, \& Johan, 2020).

The results also showed that there were more patients with anticipatory nausea who were unable to carry out normal daily activities. This is supported by Azam et al. (2019), who claimed that the patients who were unable to carry out activities were found to be higher in experiencing anticipatory nausea while undergoing chemotherapy. These patients will have a reduction in the metabolic rate causing gastrointestinal disorders. Gastric secretions can collect around and compress the lower esophageal sphincter (irritation). Therefore, bedridden patients may experience gastroesophageal reflux symptoms leading to excessive nausea (Azam et al., 2109; Yildiz, Suren, Demir \& Okan, 2019).

This study has limitations. First, the measurements were only taken two times at the beginning and at the end of hypnotherapy rather than every day. Third, confounding factors such as the giving of antiemetics could not be controlled, although the antiemetics were given after the hypnotherapy. However, a homogeneity test was carried out to minimize bias.

\section{CONCLUSION}

This study found that Hanung induction hypnotherapy decreased anticipatory nausea intensity in head and neck cancer patients undergoing chemotherapy. Hanung hypnotherapy induction intervention can be considered for use by nurses as part of nursing interventions in managing patients with anticipatory nausea. Further research can be conducted by involving a larger number of samples and enhancing the hypnotherapy session.

\section{ACKNOWLEDGEMENT}

The authors would like to express their sincere gratitude to the patients who participated in this study.

\section{CONFLICT OF INTEREST}

The authors declare no conflict of interest, financial or otherwise.

\section{REFERENCES}

Assen, A. (2016). Hypnotherapy Explained. United States: CRC Press.

Azam, F., Latif, M., Farooq, A., Tirmazy, S., Alshahrani, S., Bashir, S., \& Bukhari, N. (2019). Performance status assessment by using ECOG (Eastern Cooperative Oncology Group) score for cancer patients by oncology healthcare professionals. Case Report in Oncology, 12, 728-736. doi:10.1159/000503095 
Barber, T. X., \& Wilson, S. C. (2011). The barber suggestibility scale and the creative imagination scale. American Journal of Clinical Hypnosis, 21(2-3), 84-108. doi:10.1080/00029157.1978.10403966

Billhult, A., Bergbom, I., \& Stener-Victorin, E. (2007). Massage relieves nausea in women with breast cancer undergoing chemotherapy. Journal of Alternative and Complementary Medicine, 13(1), 53-57. doi:10.1089/ACM. 2006.6049

Booth, S. (2020). Hypnosis in a specialist palliative care setting - enhancing personalized care for difficult symptoms and situations. Palliative Care Social Practice, 14, 2632352420953436. doi:10.1177/2632352420953436.

Bray, F., Ferlay, J., Soerjomataram, I., Siegel, R. L., Torre, L. A., \& Jemal, A. (2018). Global cancer statistics 2018: Globocan estimates of incidence and mortality worldwide for 36 cancers in 185 countries. CA: A Cancer Journal for Clinicians, 68(6), 394-424. doi:10.1056/NEJMra1715715

Carlson, L. E., Toivonen, K., Flynn, M., Deleemans, J., Piedalue, K. A., Tolsdorf, E., \& Subnis, U. (2018). The role of hypnosis in cancer care. Current Oncology Reports, 20(12), 93. doi:10.1007/s11912-018-0739-1

D'Souza, G., Gross, N. D., Pai, S. I., Haddad, R., Anderson, K.S., Rajan, S., ..., \& Posner, M.R. (2014). Oral human papillomavirus (HPV) infection in HPV-positive patients with oropharyngeal cancer and their partners. Journal of Clinical Oncology, 32(23), 2408-2415. doi:10.1200/JCO.2014.55.1341

Figueroa-Moseley, C., Jean-Pierre, P., Roscoe, J. A., Ryan, J. L., Kohli, S., Palesh, O. G., ..., \& Morrow, G. R. (2012). Behavioral interventions in treating anticipatory nausea and vomiting. Journal of the National Comprehensive Cancer Network: JNCCN, 5(1), 44-50. doi:10.6004/jnccn.2007.0006

Garba., M. H., \& Mamman., M. (2019). Hypnosis and hypnotherapy: The role of traditional versus alternative approach. London: IntechOpen. doi:10.5772/intechopen.91619

Grealish, L., Lomasney, A., \& Whiteman, B. (2000). Foot massage. A nursing intervention to modify the distressing symptoms of pain and nausea in patients hospitalized with cancer. Cancer Nursing, 23(3), 237-243. doi:10.1097/00002820200006000-00012

Hakim, A. (2009). Dahsyatnya hipnosis [The power of hypnosis]. Jakarta: Visimedia.

Hamdani, D., Prasetyo, A., \& Anggorowati. (2019). Intervensi untuk mengatasi mual antisipatori pada pasien kanker yang menjalani kemoterapi: Review literatur [Interventions to treat anticipatory nausea in cancer patients undergoing chemotherapy: A literature review]. Jurnal Smart Keperawatan, 6(1), 65-72. doi:10.34310/jskp.v6i1.239

Husain, F., Kusuma, H., \& Johan, A. (2020). Effects of peer support program on selfmanagement in patients with end-stage renal disease undergoing hemodialysis. Nurse Media Journal of Nursing, 10(2), 171-181. doi:10.14710/nmjn.v10i2.26502

Janie, B., Karen, L. (2015). Philosophies and theories for advanced nursing practice. $2^{\text {nd }}$ ed. Burlington, Massachusetts: Jones \& Bartlett Learning.

Jung, H., Tae, C., Moon, C., Kim, S., \& Shim, K. (2019). Chronic unexplained nausea in adults: Prevalence, impact on the quality of life, and underlying organic diseases in a cohort of 5096 subjects comprehensively investigated. Plos One, 14(12), e0225364. doi:10.1371/journal.pone.0225364 
Kamen, C., Tejani, M. A., Chandwani, K., Janelsins, M., Peoples, A. R., \& Roscoe, J. A. (2014). Anticipatory nausea and vomiting due to chemotherapy. European Journal of Pharmacology, 722(1), 172-9. doi:10.1016/j.ejphar.2013.09.071

Kendrick, A. H. (2012). Exhaled carbon monoxide devices in smoking cessation: physiology, controversies and equipment. In: The buyers guide to respiratory care products. Bristol: Department of Respiratory Medicine-Bristol Royal Infirmary. and vomiting. Journal of the Advanced Practitioner in Oncology, 6(3), 225-229. doi:10.6004/jadpro.2015.6.3.4

Lee, K, \& Kieckhefer, G. (2011) Measuring human responses using visual analog scales. Western Journal of Nursing Research, 11, 128-132. doi:10.1177/019394598901100111

Meek, R., Kelly, A. M., \& Hu, X. F. (2009). Use of the visual analog scale to rate and monitor the severity of nausea in the emergency department. Academic emergency medicine, 16(12), 1304-1310. doi:10.1111/j.1553-2712.2009.00581.x

Ministry of Health Republic of Indonesia (MoHRI). (2018a). Laporan hasil riset kesehatan dasar (Riskesdas) Indonesia [Indonesian basic health research report]. Retrieved from http://www.kemkes.go.id

Ministry of the Health Republic of Indonesia (MoHRI). (2018b). Laporan hasil riset kesehatan dasar Provinsi Jawa Tengah [Report on Basic Health Research Results in Central Java]. Retrieved from https://www.litbang.kemkes.go.id/

Molassiotis, A., Lee, P. H., Burke, T.A., Dicato, M., Gascon, P., Roila, F., \& Aapro, M. (2016). Anticipatory nausea, risk factors, and its impact on chemotherapy-induced nausea and vomiting: Results from the Pan European emesis registry study. Journal of Pain and Symptom Management, 51(6), 987-93. doi:10.1016/j.jpainsymman.2015.12.317

Mosa, A., Hossain, A. M., Lavoie, B. J., \& Yoo, I. (2020). Patient-related risk factors for chemotherapy-induced nausea and vomiting: A systematic review. Frontiers in pharmacology, 11, 329. doi:10.3389/fphar.2020.00329

Mustian, K., Devine, K., Ryan, J., Janelsins, M., Sprod, L., Peppone, L., ..., \& Morrow, G. (2011). Treatment of nausea and vomiting during chemotherapy. US Oncology \& Hematology, 7, 91-97. doi: 10.17925/OHR.2011.07.2.91

Navari, R. M. (2016). Management of chemotherapy-induced nausea and vomiting. Switzerland: ADIS. doi:10.1007/978-3-319-27016-6

Prapti, N., Petpichetchian, W., \& Chongchareon, W. (2012). Nausea, vomiting, and retching of patients with cervical cancer undergoing chemotherapy in Bali, Indonesia. Nurse Media Journal of Nursing, 2(2), 467-481. doi:10.14710/nmjn.v2i2.3983

Prasetya, H. (2017). Intervensi medikal hipnosis sebagai upaya pemberdayaan pasien tuberkulosis untuk meningatkan kepatuhan pengobatan [Hypnosis medical intervention as an effort to empower tuberculosis patients to improve medication adherence]. Retrieved from http://sinergymindhealth.com

Prasetya, H., Murti, B., Anantanyu, S. (2018). The effect of hypnosis on adherence to antituberculosis drugs using the health belief model. International Journal of Clinical Hypnosis, 66(2), 211-27. doi:10.1080/00207144.2018.1421361

Rao, K. V., \& Faso, A. (2012). Chemotherapy-induced nausea and vomiting: optimizing prevention and management. American health \& drug benefits, 5(4), 232-240. 
Richardson, J., Smith, J. E., McCall, G., Richardson, A., Pilkington, K., \& Kirsch, I. (2007). Hypnosis for nausea and vomiting in cancer chemotherapy. European journal of cancer care, 16(5), 402-412. doi:10.1111/j.1365-2354.2006.00736.x

Robert, M. S., Kenneth, L. K., \& Paul, A. (2011). Nausea mechanisms and management. New York: Oxford University Press.

Roscoe, J. A., Morrow, G. R., Aapro, M. S., Molassiotis, A., \& Olver, I. (2011). Anticipatory nausea and vomiting. Support Care Cancer, 19(10), 1533-1538. doi:10.1007/s00520-010-0980-0

Roy, H. (2010). The art of hypnosis: Mastering basic techniques. United Kingdom: Crown house Publishing.

Stitch, MA, Rock, E. M., Limebeer, C. L., \& Parker, L. A. (2014). Endocannabinoid mechanisms influencing nausea. International Review of Biology, 125, 127-162. doi:10.1016/bs.irn.2015.09.001

Umami, A., Sudalhar, S., Pratama, T. W. Y., Fitri, I., \& Firmansyah, A. (2020). Knowledge, barriers, and motivation related to breast and cervical cancer screening among women in Bojonegoro, East Java: A qualitative study. Journal of Health Promotion and Behaviour, 5(1), 1-10. doi:10.26911/thejhpb.2020.05.01.01

Van den Bosch, J. E., Moons, K. G., Bonsel, G. J., \& Kalkman, C. J. (2010). Does Measurement of Preoperative Anxiety Have Added Value for Predicting Postoperative Nausea and Vomiting?. Anesthesia \& Analgesia, 100(5), 1525-1532 doi:10.1213/01.ANE.0000149325.20542.D4

Yildiz, C. N., Suren, M., Demir, O., \& Okan, I. (2019). Karnofsky performance scale validity and reliability of Turkish palliative cancer patients. Turkish Journal of Medical Sciences, 49(3), 894-898. doi:10.3906/sag-1810-44 